\title{
Visual movement perception: A comparison of sensitivity to vertical and horizontal movement ${ }^{1}$
}

\author{
R. A. KINCHLA, ${ }^{2}$ PRINCETON UNIVERSITY \\ AND LORAINE G. ALLAN, MCMASTER UNIVERSITY
}

\begin{abstract}
A psychophysical model that provides separate measures of judgmental standards and sensitivity is utilized to compare an $O$ 's visual sensitivity for vertical and horizontal movement. The analysis indicates no consistent difference in sensitivity; those asymmetries that do exist simply appear to be due to idiosyncratic judgmental standards.
\end{abstract}

This paper deals with one's relative ability to see vertical and horizontal movement. The possibility that movement sensitivity might not be the same in both dimensions is suggested by research on at least two types of visual phenomena, autokinesis and involuntary eye movements. The autokinetic effect is demonstrated by the apparent "illusionary" movement of a stationary point of light viewed in the dark. A commonly reported feature of such errors of movement perception is that they occur more frequently in the vertical dimension (e.g., Matin \& MacKinnon, 1964). Direct measurements of involuntary eye movements during fixation on a stationary object also seem to indicate more eye movement in the vertical dimension (St. Cyr \& Fender, 1969). However, such evidence does not necessarily indicate asymmetry in an $O$ 's sensitivity to vertical and horizontal movement. Such direct evidence can only be obtained by having an $O$ attempt to discriminate visual movement in these dimensions; i.e., it is a psychophysical question. Furthermore, the discrimination must be evaluated in such a way that judgmental and sensitivity factors are not confounded. For example, suppose an $O$ were asked to adjust the lateral velocity of a point of light until he could "just see" the movement. It can easily be shown that his setting depends both on judgmental factors and the actual velocity of the light. If he is told to be "very sure that he can really see the movement" he will tend to set the velocity higher than if he is told "even the slightest impression of movement constitutes seeing movement." Thus, it is difficult to decide whether the previously cited asymmetry in autokineses indicates an actual asymmetry in movement sensitivity or simply more liberal judgmental standards for reporting vertical movement. A psychophysical analysis of movement discrimination that provides separate measures of judgmental standards and sensitivity has been presented in an earlier paper by Kinchla and Allan (1969). The present paper utilizes this approach to compare an O's visual sensitivity for vertical and horizontal movement.

We shall consider data from two studies. The first study was conducted by the present authors and is reported here for the first time. The second study was reported by Matin and Kibler (1966). We shall reanalyze part of their data in terms of our theoretical model in order to evaluate separately the role of sensitivity and judgmental factors in their results.

\section{A MEASURE OF VISUAL} MOVEMENT SENSITIVITY, $\Phi$

The basic psychophysical task we shall consider requires an $O$ to judge the relative position of two successively presented points of light seen in an otherwise dark room. In the simplest case these two lights may differ in position along only one dimension, for example, a lateral (left-right) dimension. Thus, one light is illuminated briefly, followed some time later by a second light, and the $O$ is asked to judge their respective positions along an imaginary lateral axis. It has been shown (Kinchla \& Smyzer, 1967; Kinchla \& Allan, 1969) that the O's ability to discern a lateral separation between the two lights depends on only two physical stimulus parameters and a single theoretical constant. The stimulus parameters are: $\mathbf{m}$, the actual lateral displacement between the two lights in degrees of visual angle, and $t$, the period of darkness between the successive occurrence of the two lights. The theoretical constant, $\Phi$, may be interpreted as an inverse measure of a particular $O$ 's sensitivity to movement; i.e.. the larger the value of $\Phi$, the poorer his sensitivity.

The constant, $\Phi$, is the single theoretical parameter in a mathematical model of visual movement perception. The central assumption in this model is that each presentation of a pair of lights, a stimulus pattern, evokes some value, $\mathrm{x}$, of a hypothetical Gaussian random variable, $X$. This value may be interpreted as the "subjective impression of lateral movement," or simply, "the subjective movement." It is assumed that $\mathrm{X}$ is a sum of the actual displacement between successive lights and a Gaussian random noise variable, $\mathrm{N}$, whose expected value is zero and whose variance is directly proportional to $t$. Thus, if $S_{i}$ were some arbitrary stimulus pattern with parameters $m_{i}$ and $t_{i}$, the expected value and variance of $X$ given $S_{i}$ are defined, respectively, as

$$
\begin{aligned}
E\left(X \mid S_{i}\right) & =m_{i}+E(N) \\
& =m_{i} \\
\operatorname{Var}\left(X \mid S_{i}\right) & =\operatorname{Var}\left(N \mid t_{i}\right) \\
& =\Phi t_{i}
\end{aligned}
$$

where the "noise parameter," $\Phi$, is simply the rate at which the variancy of the noise variable, $\mathbf{N}$, increases per unit time (it is expressed in square degrees per second when $m_{j}$ is in degrees and $t$ in seconds).

A movemen: discrimination task is defined here as one in which an $O$ is asked to discriminate two stimulus patterns that differ only in the value of $m$ (while patterns that also differed in terms of $t$ might be distinguished solely on the basis of $m$, it would be difficult to exclude the possibility of a temporal discrimination). In particular we shall consider a task in which the $O$ is asked to discriminate between a stationary stimulus pattern $\mathrm{S}_{0}$ in which the successive lights occur in the same position $\left(m_{0}=0\right)$, and a nonstationary pattern $S_{1}$ in which the second light is displaced to the right of the first $(m>0$, adopting the convention that displacements to the right are positive and those to the left negative). If we denote a report of an $S_{0}$ pattern by $R_{0}$ and a report of an $S_{1}$ pattern by $R_{1}$, two useful measures of an $O$ 's performance are: $P\left(R_{1} \mid S_{0}\right)$, the proportion of $R_{1}$ responses to $S_{0}$ stimuli; and $P\left(R_{1} \mid S_{1}\right)$, the proportion of $R_{1}$ responses to $S_{1}$ stimuli.

If the theoretical distribution of $X$ given $S_{1}$ is similar to the distribution given $S_{0}$, the $O$ will have difficulty deciding whether certain $x$ values were produced by $S_{1}$ or $S_{0}$. We assume that he reports an $S_{1}$ pattern whenever $x$ exceeds some number, $\beta$, termed his response criterion. This decision process is represented graphically 


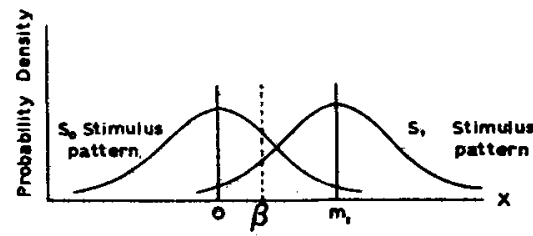

Fig. 1. Distribution of $X$ (the "impression of subjective movement") conditional upon $\mathbf{S}_{\mathbf{i}}$.

in Fig. 1, which presents hypothetical distributions of $X$ given $S_{0}$ or $S_{1}$ and an arbitrary value of $\beta$. The areas to the right of $\beta$ correspond to the probability that $x$ exceeds $\beta$ given each stimulus pattern, i.e., to $P\left(R_{1} \mid S_{1}\right)$ and $P\left(R_{1} \mid S_{0}\right)$.

While the model is similar to the psychophysical theory of signal detection described by Green and Swets (1966), it has a unique time-dependent feature whereby the "overlap" between the two distributions in Fig. 1 increases during the $t-\sec$ interlight interval. Specifically, if we express the distance between the two means in Fig. 1 in units of the standard deviation of $X$, we can define a discriminability measure, $\mathrm{D}$, analogous to the " $d$ "' measure of Green and Swets:

$$
\begin{aligned}
D & =\frac{E\left(X \mid S_{1}\right)-E\left(X \mid S_{0}\right)}{[\operatorname{Var}(X)]^{1 / 2}} \\
& =\frac{m_{1}}{(\Phi t)^{1 / 2}}
\end{aligned}
$$

Thus $\mathrm{D}$ is directly related to $\mathrm{m}_{1}$ and inversely related to $t^{1 / 2}$. The theoretical constant $\Phi$ is an inverse measure of sensitivity since it specifies how rapidly the variance of $X$ increases during the interlight interval. The more variance, the greater the similarity or "overlap" between the two distributions in Fig. 1, and the more difficult the discrimination.

An important property of $D$ is that it can be estimated directly from an O's performance regardless of his choice of response criterion. If $\hat{L}_{i}$ is that value of a normal deviate exceeded with a probability equal to $\hat{\mathrm{P}}\left(\mathrm{R}_{1} \mid \mathrm{S}_{\mathrm{i}}\right)$, for $\mathrm{i}$ equal 0 or 1 , then an estimate of $\mathrm{D}$, denoted $\hat{\mathrm{D}}$, is given by the difference between $\hat{z}_{0}$ and $\hat{z}_{1}$ :

$$
\hat{\mathrm{D}}=\hat{\mathrm{z}}_{0}-\hat{\mathrm{z}}_{1} \text {. }
$$

(This follows directly from the geometry of the Gaussian distributions in Fig. 1). Furthermore, by rearranging Eq. 3 and substituting $\hat{D}$ for $D$, it is possible to define an estimate of $\Phi$ denoted by $\hat{\phi}$ :

$$
\hat{\Phi}=\frac{m_{1}^{2}}{\hat{D}^{2} t}
$$

The measure $\dot{\Phi}$ allows one to specify the discriminability of $S_{0}$ and any other nonstationary pattern $S_{1}$ by Eq. 3 for any value of $m_{1}$ and $t$. Furthermore, although $\hat{\Phi}$ has been defined here in terms of discrete movement patterns consisting of successively illuminated static points of light, it also seems to eharacterize an 0 's sensitivity to continuous movement patterns consisting of continuously moving points of light. For example, suppose an $S_{1}$ pattern were defined as a light that came on for $t$ sec during which time it moved $m_{1}$ deg to the right at a fixed angular velocity of $v_{1} \mathrm{deg} / \mathrm{sec}$ (i.e., $v_{1}=m_{1} / t$ ), while an $S_{0}$ pattern was a light that simply remained stationary during a similar $t$-sec illumination (i.e., $m_{0}=v_{0}=0$ ). Equation 3 could be rewritten in a continuous movement form by utilizing the identity $v_{1}$ equal to $m_{1}$ divided by $t$ :

$$
D=\frac{v_{1} t^{1 / 2}}{\Phi^{1 / 2}}
$$

Not only does this relation appear to hold for continuous movement discriminations but the value of $\dot{\Phi}$ appears to be of the same magnitude as found in discrete movement discrimination (Kinchla \& Allan, 1969).

Finally, it should be emphasized that $\dot{\boldsymbol{\phi}}$ characterizes an $O$ 's ability to perceive the linear displacement of a point in an otherwise dark or homogeneous visual field (Ganzfeld). This process of absolute movement perception should be distinguished from relative movement perception where the movement of one object in the visual field is judged relative to the position of another object. This distinction is developed further in papers by Kinchla (1968) and Kinchla \& Allan (1969).

\section{AN EXPERIMENT INVOLVING TWO-DIMENSIONAL MOVEMENT}

This study utilized a two-dimensional form of the one-dimensional movement discrimination task. Here the second light in each stimulus pattern could be displaced on either the horizontal or vertical dimensions. Specifically, one of four equally probable stimulus patterns was presented on each test trial: an $S_{00}$ pattern, in which the second light was in the same position as the first (i.e., a stationary pattern); an $S_{01}$ pattern, in which the second light was displaced $.4 \mathrm{deg}$ to the right of the first; an $S_{10}$ pattern, in which the second light was displaced downward .4 deg; and an $S_{11}$ pattern, in which the second light was displaced downward $.4 \mathrm{deg}$ as well as $.4 \mathrm{deg}$ to the right. The O's task was to decide which of these four $S_{i j}$ patterns had occurred on each trial. Thus we can denote his report of an $S_{i j}$ pattern by $R_{j j}$. Data were obtained at four interlight delays ( $t$ values): $.5,1.0$, 1.5 , and 2 sec.

\section{Procedure}

The stimulus lights were tungsten filament "indicator" lamps (Dialco No. 39) with a flat circular surface of white opal glass. They were located $4.1 \mathrm{~m}$ in front of the $O$, where they subtended $.033 \mathrm{deg}$ of visual angle. The lights were clearly visible at about $4 \mathrm{~mL}$, although not bright enough to reveal any other details in the otherwise dark testing room. The $O$ sat in a conventional desk chair, with no special constraints on head movements, and viewed the stimuli binocularly.

Each daily testing session was divided into five successive blocks of 100 trials with a 1-min rest period in the dark between blocks. Each trial began with a clearly audible 1 -sec $500-\mathrm{Hz}$ auditory "warning" tone followed immediately by the visual stimulus pattern. The $O$ then had $2 \mathrm{sec}$ in which to indicate his judgment regarding that stimulus by pressing one of four buttons prior to the start of the next trial. The four $S_{i j}$ patterns occurred equally often in a randomly determined sequence within each block of trials. Each of the lights in the stimulus pattern was on for $100 \mathrm{msec}$ and the interlight delay (t) was constant within any particular session at .5 , $1.0,1.5$, or 2 sec. Five paid Os were each tested for 20 sessions, 5 under each of the four $t$ values. Each $t$ value occurred once within each series of 4 sessions in a randomly determined order. Only the last 400 trials of each 0 's last 16 sessions were used in the data analysis. This allowed 4 preliminary "practice" sessions and one block of "warmup" trials at the beginning of each session.

The Os were completely familiar with the nature of the stimulus patterns and the randomization process.

\section{Results}

An $O$ 's tendency to make an $R_{1}$, response to an $S_{11}$ stimulus is indicated by the proportion of such responses to that pattern. This proportion will be denoted here by $\hat{P}\left(R_{1}, \mid S_{11}\right)$ and interpreted as an estimate of the corresponding conditional probability $P\left(R_{1} \mid S_{11}\right)$. Similar proportions can be calculated for each of 
Table 1

Proportions of Each Response to Each Stimulus Pattem for Each Observer Under Each Value of $t$

\begin{tabular}{|c|c|c|c|c|c|c|c|c|c|c|c|c|c|c|c|c|c|}
\hline \multirow[b]{2}{*}{ Obs. } & \multirow[b]{2}{*}{$t$} & \multicolumn{4}{|c|}{$S_{11}$} & \multicolumn{4}{|c|}{$S_{10}$} & \multicolumn{4}{|c|}{$\mathrm{S}_{01}$} & \multicolumn{4}{|c|}{$S_{00}$} \\
\hline & & $R_{11}$ & $R_{10}$ & $\mathbf{R}_{\mathbf{0 1}}$ & $\mathbf{R}_{\mathbf{0 0}}$ & $R_{11}$ & $R_{10}$ & $\mathbf{R}_{01}$ & $\mathbf{R}_{\mathbf{0 0}}$ & $R_{11}$ & $R_{10}$ & $\mathbf{R}_{\mathbf{0}_{1}}$ & $\mathbf{R}_{\mathbf{0 0}}$ & $R_{11}$ & $R_{10}$ & $R_{01}$ & $\mathbf{R}_{00}$ \\
\hline 1 & $\begin{array}{r}.5 \\
1.0 \\
1.5 \\
2.0\end{array}$ & $\begin{array}{l}.324 \\
.278 \\
.264 \\
.242\end{array}$ & $\begin{array}{l}.304 \\
.301 \\
.245 \\
.242\end{array}$ & $\begin{array}{l}.249 \\
.231 \\
.320 \\
.339\end{array}$ & $\begin{array}{l}.122 \\
.191 \\
.172 \\
.176\end{array}$ & $\begin{array}{l}.146 \\
.148 \\
.155 \\
.167\end{array}$ & $\begin{array}{l}.506 \\
.438 \\
.412 \\
.341\end{array}$ & $\begin{array}{l}.111 \\
.160 \\
.186 \\
.221\end{array}$ & $\begin{array}{l}.238 \\
.254 \\
.247 \\
.271\end{array}$ & $\begin{array}{l}.099 \\
.122 \\
.167 \\
.153\end{array}$ & $\begin{array}{l}.118 \\
.158 \\
.122 \\
.146\end{array}$ & $\begin{array}{l}.475 \\
.419 \\
.414 \\
.412\end{array}$ & $\begin{array}{l}.308 \\
.301 \\
.296 \\
.289\end{array}$ & $\begin{array}{l}.052 \\
.092 \\
.106 \\
.099\end{array}$ & $\begin{array}{l}.216 \\
.200 \\
.202 \\
.202\end{array}$ & $\begin{array}{l}.202 \\
.252 \\
.322 \\
.306\end{array}$ & $\begin{array}{r}.529 \\
.456 \\
.369 \\
.393\end{array}$ \\
\hline 2 & $\begin{array}{r}.5 \\
1.0 \\
1.5 \\
2.0\end{array}$ & $\begin{array}{l}.468 \\
.365 \\
.306 \\
.296\end{array}$ & $\begin{array}{r}.176 \\
.179 \\
.240 \\
.254\end{array}$ & $\begin{array}{l}.282 \\
.308 \\
.308 \\
.266\end{array}$ & $\begin{array}{l}.073 \\
.148 \\
.146 \\
.184\end{array}$ & $\begin{array}{l}.134 \\
.136 \\
.160 \\
.160\end{array}$ & $\begin{array}{l}.508 \\
.419 \\
.362 \\
.341\end{array}$ & $\begin{array}{l}.073 \\
.122 \\
.188 \\
.169\end{array}$ & $\begin{array}{l}.284 \\
.322 \\
.289 \\
.329\end{array}$ & $\begin{array}{l}.101 \\
.101 \\
.132 \\
.144\end{array}$ & $\begin{array}{l}.042 \\
.064 \\
.101 \\
.132\end{array}$ & $\begin{array}{l}.661 \\
.581 \\
.508 \\
.466\end{array}$ & $\begin{array}{l}.195 \\
.254 \\
.259 \\
.259\end{array}$ & $\begin{array}{l}.042 \\
.085 \\
.073 \\
.073\end{array}$ & $\begin{array}{l}.093 \\
.158 \\
.167 \\
.172\end{array}$ & $\begin{array}{l}.218 \\
.195 \\
.212 \\
.224\end{array}$ & $\begin{array}{l}.648 \\
.562 \\
.548 \\
.532\end{array}$ \\
\hline 3 & $\begin{array}{r}.5 \\
1.0 \\
1.5 \\
2.0\end{array}$ & $\begin{array}{l}.464 \\
.296 \\
.320 \\
.296\end{array}$ & $\begin{array}{l}.238 \\
.294 \\
.320 \\
.329\end{array}$ & $\begin{array}{l}.247 \\
.271 \\
.230 \\
.231\end{array}$ & $\begin{array}{l}.052 \\
.139 \\
.129 \\
.144\end{array}$ & $\begin{array}{l}.087 \\
.092 \\
.134 \\
.146\end{array}$ & $\begin{array}{l}.595 \\
.454 \\
.459 \\
.482\end{array}$ & $\begin{array}{l}.054 \\
.125 \\
.145 \\
.096\end{array}$ & $\begin{array}{l}.264 \\
.329 \\
.261 \\
.275\end{array}$ & $\begin{array}{l}.073 \\
.148 \\
.127 \\
.146\end{array}$ & $\begin{array}{l}.073 \\
.141 \\
.172 \\
.216\end{array}$ & $\begin{array}{l}.685 \\
.522 \\
.489 \\
.395\end{array}$ & $\begin{array}{l}.169 \\
.188 \\
.212 \\
.242\end{array}$ & $\begin{array}{l}.019 \\
.075 \\
.073 \\
.099\end{array}$ & $\begin{array}{l}.094 \\
.158 \\
.266 \\
.216\end{array}$ & $\begin{array}{l}.118 \\
.252 \\
.233 \\
.247\end{array}$ & $\begin{array}{l}.769 \\
.515 \\
.428 \\
.438\end{array}$ \\
\hline 4 & $\begin{array}{r}.5 \\
1.0 \\
1.5 \\
2.0\end{array}$ & $\begin{array}{l}.504 \\
.336 \\
.348 \\
.318\end{array}$ & $\begin{array}{l}.209 \\
.332 \\
.280 \\
.320\end{array}$ & $\begin{array}{l}.207 \\
.188 \\
.221 \\
.200\end{array}$ & $\begin{array}{l}.080 \\
.144 \\
.151 \\
.162\end{array}$ & $\begin{array}{l}.122 \\
.122 \\
.144 \\
.155\end{array}$ & $\begin{array}{l}.525 \\
.506 \\
.475 \\
.445\end{array}$ & $\begin{array}{l}.096 \\
.111 \\
.108 \\
.153\end{array}$ & $\begin{array}{l}.256 \\
.261 \\
.273 \\
.247\end{array}$ & $\begin{array}{l}.082 \\
.111 \\
.134 \\
.186\end{array}$ & $\begin{array}{l}.080 \\
.108 \\
.111 \\
.205\end{array}$ & $\begin{array}{l}.685 \\
.520 \\
.466 \\
.362\end{array}$ & $\begin{array}{l}.153 \\
.261 \\
.289 \\
.247\end{array}$ & $\begin{array}{l}.019 \\
.071 \\
.120 \\
.134\end{array}$ & $\begin{array}{l}.127 \\
.224 \\
.198 \\
.231\end{array}$ & $\begin{array}{l}.198 \\
.160 \\
.184 \\
.238\end{array}$ & $\begin{array}{r}.656 \\
.546 \\
.499 \\
.398\end{array}$ \\
\hline 5 & $\begin{array}{r}.5 \\
1.0 \\
1.5 \\
2.0 \\
\end{array}$ & $\begin{array}{l}.652 \\
.445 \\
.416 \\
.402 \\
\end{array}$ & $\begin{array}{r}.085 \\
.174 \\
.169 \\
.207 \\
\end{array}$ & $\begin{array}{r}.219 \\
.247 \\
.301 \\
.264 \\
\end{array}$ & $\begin{array}{l}.045 \\
.134 \\
.113 \\
.127 \\
\end{array}$ & $\begin{array}{r}.245 \\
.174 \\
.238 \\
.252 \\
\end{array}$ & $\begin{array}{l}.525 \\
.445 \\
.393 \\
.376 \\
\end{array}$ & $\begin{array}{l}.066 \\
.085 \\
.139 \\
.125 \\
\end{array}$ & $\begin{array}{l}.165 \\
.296 \\
.230 \\
.247\end{array}$ & $\begin{array}{l}.120 \\
.174 \\
.205 \\
.200 \\
\end{array}$ & $\begin{array}{l}.012 \\
.052 \\
.056 \\
.094\end{array}$ & $\begin{array}{l}.713 \\
.536 \\
.504 \\
.520\end{array}$ & $\begin{array}{l}.155 \\
.238 \\
.235 \\
.186\end{array}$ & $\begin{array}{l}.068 \\
.104 \\
.110 \\
.141\end{array}$ & $\begin{array}{l}.064 \\
.104 \\
.162 \\
.195\end{array}$ & $\begin{array}{l}.148 \\
.139 \\
.252 \\
.259\end{array}$ & $\begin{array}{l}.720 \\
.654 \\
.475 \\
.405\end{array}$ \\
\hline
\end{tabular}

the 16 possible stimulus-response combinations. These proportions are presented in Table 1 for each $O$ under each $t$ value.

It is also possible to categorize the responses in terms of their implication concerning movement in a single dimension. For example, just as an $S_{11}$ and $S_{01}$ stimulus pattern are equivalent in terms of the horizontal displacement of the second light, $R_{11}$ and $R_{01}$ are equivalent in that they both constitute a report of a horizontal displacement. For this reason we shall refer to both $S_{1_{1}}$ and $S_{0_{1}}$ as $S_{x}$ stimuli, and to both $R_{11}$ and $R_{01}$ as $R_{X}$ responses. Thus the proportion of $R_{x}$ responses on $S_{x}$ trials, $\hat{P}\left(R_{x} \mid S_{x}\right)$, indicates the $O$ 's tendency to report movement on the horizontal $(x)$ dimension when it actually occurred, while the proportion of $R_{x}$ responses on $\bar{S}_{x}$ (non- $S_{x}: S_{10}$ or $S_{00}$ ) trials, $P\left(R_{x} \mid \bar{S}_{x}\right)$, indicates his tendency to report horizontal movement when none had occurred. An analogous notation will be employed to organize the data in terms of movement on the vertical ( $y$ ) dimension. For example, $\hat{P}\left(R_{y} \mid S_{y}\right)$ will denote the proportion of $R_{y}$ responses (either $R_{10}$ or $R_{11}$ ) to $S_{y}$ stimuli (either $S_{10}$ or $S_{11}$ ). It is also of interest to consider how often an $O$ 's response correctly identified the actual displacement of the second light on each dimension. This is given by two proportions, $\hat{\mathbf{Y}}\left(\mathrm{C}_{\mathrm{x}}\right)$ and $\hat{\mathbf{P}}\left(\mathrm{C}_{\mathrm{y}}\right)$, with

$\dot{\mathbf{P}}\left(\mathrm{C}_{\mathbf{x}}\right)=\mathbf{P}\left(\mathbf{S}_{\mathbf{x}}\right) \hat{\mathbf{P}}\left(\mathbf{R}_{\mathbf{x}} \mid \mathbf{S}_{\mathbf{x}}\right)+\mathbf{P}\left(\overline{\mathbf{S}}_{\mathbf{x}}\right) \dot{\mathbf{P}}\left(\overline{\mathbf{R}}_{\mathbf{x}} \mid \overline{\mathbf{S}}_{\mathbf{x}}\right)$

and

$\hat{\mathrm{P}}\left(\mathrm{C}_{\mathrm{y}}\right)=\mathrm{P}\left(\mathrm{S}_{\mathrm{y}}\right) \hat{\mathbf{P}}\left(\mathbf{R}_{\mathrm{y}} \mid \mathrm{S}_{\mathrm{y}}\right)+\mathbf{P}\left(\overline{\mathbf{S}}_{\mathrm{y}}\right) \hat{\mathbf{P}}\left(\overline{\mathrm{R}}_{\mathrm{y}} \mid \mathrm{S}_{\mathrm{y}}\right)$

(Note that $\mathbf{P}\left(\mathbf{S}_{\mathrm{x}}\right), \mathbf{P}\left(\mathbf{S}_{\mathrm{y}}\right), \mathbf{P}\left(\overline{\mathbf{S}}_{\mathrm{x}}\right)$, and $\mathbf{P}\left(\overline{\mathbf{S}}_{\mathrm{y}}\right)$, the proportions of each type of stimulus trial, all equal .5 since each type of pattern occurred equally often). The preceding "one-dimensional" statistics for each $\mathrm{O}$ at each $t$ value are presented in Table 2 .

A conventional chi-square analysis is sufficient to demonstrate a statistically significant $(p<.01)$ effect of both the stimulus variable $\left(S_{i j}\right)$ and interlight delay $(t)$ on each $O$ 's performance. The general nature of this effect is apparent in Table 1 , where the proportion of $R_{i j}$ responses to an $S_{i j}$ pattern typically exceeds that of any other response at all $t$ values for all four $S_{\mathrm{ij}}$. This is true in almost every case, although the size of the difference is inversely related to the interlight interval $t$.
This effect is also evident in Table 2 , where the proportions of correct judgments in each dimension, $\hat{\mathrm{P}}\left(\mathrm{C}_{\mathrm{x}}\right)$ and $\hat{\mathrm{P}}\left(\mathrm{C}_{y}\right)$, diminish as $t$ increases for all five Os. Thus all five Os demonstrated partial discrimination, which grew poorer as $t$ was increased.

An important feature of the data is the degree to which responses concerning vertical and horizontal movement appear to be statistically independent; i.e., to what degree is the classification of a particular response $R_{i j}$ as $R_{x}$ or $R_{\bar{x}}$ independent of its classification as $R_{y}$ or $R_{\bar{y}}$ ? To answer this question, a Pearson chi-square test of association (see Hays, 1963, pp. 589-592) was calculated for each $O$. These statistics indicated a negligible but statistically significant $(\mathrm{p}<.05)$ departure from

Table 2

One-Dimensional Response Statistics Based on the Data in Table 1

\begin{tabular}{|c|c|c|c|c|c|c|c|}
\hline \multirow[b]{2}{*}{ Obs. } & \multirow[b]{2}{*}{$\mathrm{t}$} & \multicolumn{3}{|c|}{ Vertical } & \multicolumn{3}{|c|}{ Horizontal } \\
\hline & & $\hat{P}\left(R_{y} \mid S_{y}\right)$ & $\hat{\mathbf{P}}\left(R_{y} \mid \vec{S}_{y}\right)$ & $\hat{\mathbf{P}}\left(\mathrm{C}_{\mathrm{y}}\right)$ & $\hat{\mathbf{P}}\left(\mathbf{R}_{\mathrm{X}} \mid \mathbf{S}_{\mathrm{X}}\right)$ & $\hat{\boldsymbol{P}}\left(\mathbf{R}_{\mathrm{X}} \mid \overline{\mathbf{S}}_{\mathrm{X}}\right)$ & $\hat{\mathbf{P}}\left(\mathrm{C}_{\mathrm{X}}\right)$ \\
\hline 1 & $\begin{array}{r}.5 \\
1.0 \\
1.5 \\
2.0\end{array}$ & $\begin{array}{l}.64 \\
.58 \\
.54 \\
.50\end{array}$ & $\begin{array}{l}.24 \\
.28 \\
.30 \\
.30\end{array}$ & $\begin{array}{l}.70 \\
.65 \\
.62 \\
.60\end{array}$ & $\begin{array}{l}.57 \\
.52 \\
.58 \\
.57\end{array}$ & $\begin{array}{l}.26 \\
.32 \\
.38 \\
.40\end{array}$ & $\begin{array}{l}.66 \\
.60 \\
.60 \\
.58\end{array}$ \\
\hline 2 & $\begin{array}{l}.5 \\
1.0 \\
1.5 \\
2.0\end{array}$ & $\begin{array}{l}.64 \\
.55 \\
.53 \\
.52\end{array}$ & $\begin{array}{l}.14 \\
.20 \\
.24 \\
.26\end{array}$ & $\begin{array}{l}.75 \\
.68 \\
.64 \\
.63\end{array}$ & $\begin{array}{l}.76 \\
.68 \\
.63 \\
.58\end{array}$ & $\begin{array}{l}.23 \\
.27 \\
.32 \\
.31\end{array}$ & $\begin{array}{l}.76 \\
.70 \\
.66 \\
.64\end{array}$ \\
\hline 3 & $\begin{array}{r}.5 \\
1.0 \\
1.5 \\
2.0\end{array}$ & $\begin{array}{l}.69 \\
.57 \\
.62 \\
.63\end{array}$ & $\begin{array}{l}.13 \\
.26 \\
.32 \\
.34\end{array}$ & $\begin{array}{l}.78 \\
.66 \\
.65 \\
.64\end{array}$ & $\begin{array}{l}.73 \\
.62 \\
.58 \\
.53\end{array}$ & $\begin{array}{l}.14 \\
.27 \\
.29 \\
.29\end{array}$ & $\begin{array}{l}.80 \\
.68 \\
.64 \\
.62\end{array}$ \\
\hline 4 & $\begin{array}{r}.5 \\
1.0 \\
1.5 \\
2.0\end{array}$ & $\begin{array}{l}.68 \\
.65 \\
.62 \\
.62\end{array}$ & $\begin{array}{l}.15 \\
.26 \\
.28 \\
.38\end{array}$ & $\begin{array}{l}.76 \\
.70 \\
.67 \\
.62\end{array}$ & $\begin{array}{l}.74 \\
.58 \\
.58 \\
.53\end{array}$ & $\begin{array}{l}.22 \\
.23 \\
.28 \\
.34\end{array}$ & $\begin{array}{l}.76 \\
.68 \\
.65 \\
.60\end{array}$ \\
\hline 5 & $\begin{array}{l}.5 \\
1.0 \\
1.5 \\
2.0 \\
\end{array}$ & $\begin{array}{l}.75 \\
.62 \\
.61 \\
.62 \\
\end{array}$ & $\begin{array}{l}.13 \\
.22 \\
.27 \\
.32 \\
\end{array}$ & $\begin{array}{l}.81 \\
.70 \\
.67 \\
.65 \\
\end{array}$ & $\begin{array}{l}.85 \\
.70 \\
.71 \\
.69 \\
\end{array}$ & $\begin{array}{l}.26 \\
.25 \\
.37 \\
.39 \\
\end{array}$ & $\begin{array}{l}.80 \\
.72 \\
.67 \\
.65 \\
\end{array}$ \\
\hline
\end{tabular}


Table 3

Estimated and Predicted Values of $D$ for Each Observer

\begin{tabular}{|c|c|c|c|c|c|c|c|c|c|c|c|c|c|c|c|}
\hline \multirow[b]{2}{*}{$\mathbf{t}$} & \multicolumn{3}{|c|}{ Observer 1} & \multicolumn{3}{|c|}{ Observer 2} & \multicolumn{3}{|c|}{ Observer 3} & \multicolumn{3}{|c|}{ Observer 4} & \multicolumn{3}{|c|}{ Observer 5} \\
\hline & $\hat{D}_{y}$ & $\hat{\mathbf{D}}_{\mathbf{X}}$ & $\begin{array}{c}\text { Predicted } \\
(\dot{\Phi}=.360)\end{array}$ & $\hat{\mathrm{D}}_{\mathbf{y}}$ & $\dot{\mathbf{D}}_{\mathrm{x}}$ & $\begin{array}{r}\text { Predicted } \\
(\hat{\Phi}=.157)\end{array}$ & $\hat{\mathbf{D}}_{\mathrm{y}}$ & $\hat{\mathbf{D}}_{\mathbf{X}}$ & $\begin{array}{r}\text { Predicted } \\
(\hat{\Phi}=.148) \\
\end{array}$ & $\hat{\mathbf{D}}_{\mathrm{y}}$ & $\hat{\mathbf{D}}_{\mathbf{X}}$ & $\begin{array}{r}\text { Predicted } \\
(\Phi=.164) \\
\end{array}$ & $\hat{D}_{y}$ & $\hat{\mathbf{D}}_{\mathbf{x}}$ & $\begin{array}{c}\text { Predicted } \\
(\dot{\Phi}=.117)\end{array}$ \\
\hline .5 & 1.06 & .82 & .94 & 1.44 & 1.44 & 1.43 & 1.64 & 1.69 & 1.47 & 1.51 & 1.41 & 1.40 & 1.80 & 1.68 & 1.65 \\
\hline 1.0 & .78 & .52 & .67 & .97 & 1.08 & 1.01 & .82 & .92 & 1.04 & 1.02 & .94 & .99 & 1.08 & 1.20 & 1.17 \\
\hline 1.5 & .62 & .50 & .54 & .78 & .80 & .82 & .78 & .76 & .85 & .88 & .78 & .81 & .89 & .88 & .95 \\
\hline 2.0 & .52 & .44 & .47 & .69 & .70 & .71 & .74 & .63 & .74 & .61 & .48 & .70 & .78 & .78 & .83 \\
\hline
\end{tabular}

independence for all five Os. However, the product moment correlation (r) between each $O$ 's vertical responses and his horizontal responses (see Hays, 1963, pp. 604-606 for a detailed discussion of this statistic) was only $.112, .039, .126$, .073 , and .073 for Os $1-5$, respectively. In other words, the fact that each proportion in Table 1 is based on 1,600 trials allows us to demonstrate the statistical significance of an extremely weak correlation between vertical and horizontal judgments.

Further discussion of the results can best be done in terms of the theoretical model.

\section{Theoretical Analysis}

With a few additional assumptions, it is possible to apply the one-dimensional movement model to this two-dimensional task. Specifically, we shall assume that the "subjective movement" produced by a two-dimensional pattern is represented by the values $x$ and $y$ of two Gaussian random variables, $X$ and $Y$. The expected value and variance of each variable will be related to the actual horizontal (X) and vertical (Y) displacement of the second light in each stimulus pattern, and to the "noise" on each dimension, in the same fashion as in the one-dimensional case (i.e., as stated in Eqs. 1 and 2). Thus, there are two noise variables, $\mathrm{N}_{\mathrm{x}}$ and $\mathrm{N}_{\mathrm{y}}$, and two noise parameters, $\Phi_{x}$ and $\Phi_{y}$. We shall also
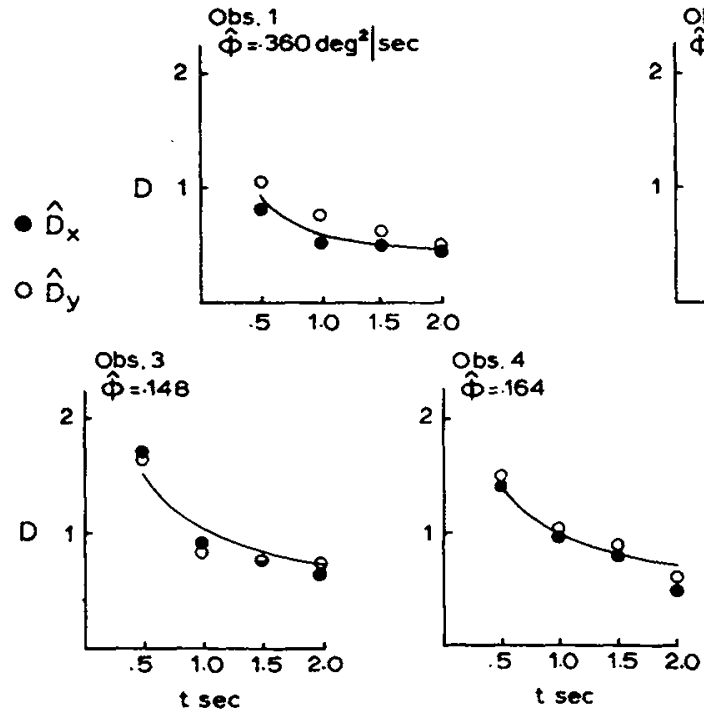
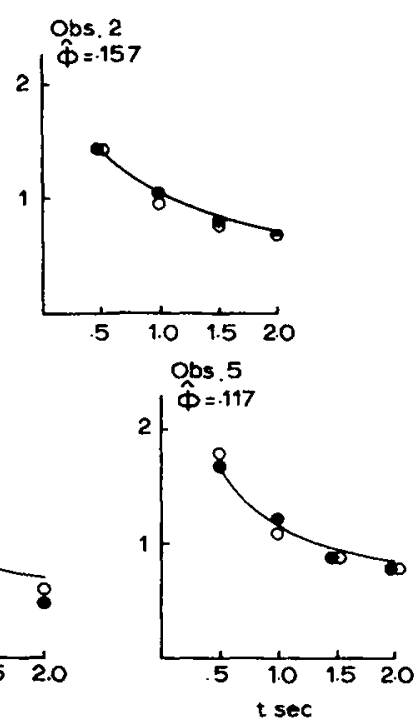

assume that the $O$ makes independent judgments of movement on the horizontal and vertical dimensions, reporting horizontal movement whenever $x$ exceeds his horizontal movement criterion $\beta_{\mathrm{x}}$, and vertical movement whenever y exceeds his vertical movement criterion $\beta_{y}$. Note that this assumption does not imply a zero correlation between responses on the two dimensions, since a correlation be tween $\mathrm{N}_{\mathbf{x}}$ and $\mathrm{N}_{\mathrm{y}}$ would produce a response correlation. Thus, the weak response correlations reported in the preceding section will be interpreted as reflecting a small common noise component in $\mathrm{N}_{\mathrm{X}}$ and $N_{y}$. (Even if the noise variables were really independent, the very weak response correlations would represent a negligible departure from the independent decisions assumption.)

Our assumptions concerning the two-dimensional task imply that proportions $\hat{P}\left(R_{1} \mid S_{1}\right)$ and $\hat{P}\left(R_{1} \mid S_{0}\right)$ in the one-dimensional task are represented here by $\hat{\mathbf{P}}\left(R_{y} \mid S_{y}\right)$ and $\hat{\mathbf{P}}\left(R_{y} \mid S_{y}\right)$ if we consider vertical judgments or by $\hat{\mathrm{P}}\left(\mathrm{R}_{\mathrm{X}} \mid \mathrm{S}_{\mathrm{x}}\right)$ and $\hat{\mathrm{P}}\left(\mathrm{R}_{\mathrm{x}} \mid \overline{\mathrm{S}}_{\mathrm{x}}\right)$ if we consider horizontal judgments. Estimates of the discriminability in each dimension, denoted $\hat{\mathfrak{D}}_{\mathrm{x}}$ and $\hat{\mathfrak{D}}_{\mathrm{y}}$, can therefore be calculated on the basis of Eq. 4 and the appropriate proportions from Table 2. These estimates are presented numerically in Table 3 and graphically in Fig. 2. Consideration of the complete set of data leads to two general conclusions: first, discriminability (D) diminishes as the interlight delay is increased, and second, there is no consistent superiority of discrimination in one dimension over that in the other. The performances of Os 1 and 4 do suggest a slight superiority in vertical discriminability $\left(\mathrm{D}_{\mathrm{y}}>\hat{D}_{\mathrm{x}}\right)$, but there is no suggestion of such a difference in the data from the other three Os. Consequently, a single estimate of $\Phi$, denoted $\hat{\boldsymbol{\phi}}$, was calculated for both the vertical and horizontal judgments (i.e., $\hat{\Phi}_{x}=\hat{\Phi}_{y}=\hat{\phi}$ ) for each $O$. This was done by choosing $\hat{\Phi}$ to minimize the sum of squared discrepancies between the $\hat{\mathbf{D}}$ values in Table 3 and those predicted by Eq. 3. The estimates of $\Phi$ for Os 1 through 5 , respectively, were: $.360, .157, .148, .164$, and $.117 \mathrm{sq} \mathrm{deg} / \mathrm{sec}$. These values are generally consistent with those obtained in the earlier studies of one-dimensional movement discrimination (see Kinchla \& Allan, 1969). The predicted values of $D$ based on these estimates are presented numerically in Table 3 and as a theoretical curve in Fig. 1. It is clear that the single measure $\hat{\mathbf{q}}$ provides a reasonable account of discriminability at all $t$ values for each $O$, although the data from $\mathrm{O} I$ could be better fitted by separate estimates of $\Phi_{x}$ and $\Phi_{y}$. In any case, there is no clear basis for rejecting the assumption that $\Phi_{x}$ is generally equal to $\Phi_{y}$, even though individual Os may show slightly greater sensitivity (lower $\Phi$ ) in one dimension.

It is also interesting to consider the response criteria $\left(\beta_{x}\right.$ and $\left.\beta_{y}\right)$ adopted by each $O$ at each $t$ value. Estimates of these values, denoted $\hat{\beta}_{\mathrm{x}}$ and $\hat{\beta}_{\mathrm{y}}$, were obtained for each $O$ by finding that $\beta$ value which was most consistent (in a least-squares sense) with the performance at each $t$ value given his particular value of $\dot{\phi}$ (this estimation procedure is developed in detail in Kinchla and Allan, 1969). These estimates are presented numerically in Table 4 and graphically in Fig. 3. While there were no consistent differences

Fig. 2. Estimated and predicted values of D for each 0 . 
Table 4

Estimated Values of $\beta_{y}$ and $\beta_{x}$ in Degrees Visual Angle for Each Observer at Each $t$ Value

\begin{tabular}{|c|c|c|c|c|c|c|c|c|c|c|}
\hline \multirow[b]{2}{*}{$t$} & \multicolumn{2}{|c|}{ Observer 1} & \multicolumn{2}{|c|}{ Observer 2} & \multicolumn{2}{|c|}{ Observer 3} & \multicolumn{2}{|c|}{ Observer 4} & \multicolumn{2}{|c|}{ Observer 5} \\
\hline & $\hat{\beta}_{y}$ & $\hat{\beta}_{X}$ & $\hat{\beta}_{y}$ & $\hat{\beta}_{X}$ & $\dot{\beta}_{y}$ & $\hat{\beta}_{\mathbf{X}}$ & $\hat{\beta}_{y}$ & $\hat{\beta}_{\mathrm{X}}$ & $\dot{\beta}_{y}$ & $\hat{\beta}_{x}$ \\
\hline .5 & .28 & .30 & .30 & .21 & .28 & .26 & .28 & .22 & .25 & .15 \\
\hline 1.0 & .32 & .32 & .35 & .23 & .28 & .26 & .25 & .31 & .28 & .23 \\
\hline 1.5 & .34 & .24 & .36 & .23 & .25 & .29 & .27 & .30 & .27 & .15 \\
\hline 2.0 & .42 & .24 & .38 & .29 & .22 & .33 & .20 & .30 & .24 & .15 \\
\hline
\end{tabular}

between $\dot{\Phi}_{\mathrm{x}}$ and $\Phi_{\mathrm{y}}$ across all Os, there were individual features of some interest. Specifically, note that $\hat{\beta}_{y}$ is consistently greater than $\hat{\beta}_{x}$ for both Ö 2 and 5 . Even though each of them appears to have had equal sensitivity to movement in either dimension, they were more cautious about reporting vertical movement. For example, when $\mathrm{t}$ was $.5 \mathrm{sec}, \mathrm{O} 2$ required at least 30 rdeg of "subjective movement" $(y>30)$ to report vertical movement, whereas he required only $.21 \mathrm{deg}(\mathrm{x}>.21)$ to report horizontal movement. Thus, the fact that both Os reported "autokinetic movement" (reported movement when none had occurred) more witen in the horizontal dimension [see $P\left(R_{y} \mid \bar{S}_{y}\right)$ and $P\left(R_{x} \mid \bar{S}_{x}\right)$ in Table 2] seems due to an asymmetry in judgmental standards $(\beta$ values) rather than sensitivity ( $\Phi$ values).

\section{REANALYSIS OF \\ SOME RELATED DATA}

We shall now consider part of a study reported by Matin and Kibler (1966): the performance of three Os on both a vertical and horizontal form of a one-dimensional, discrete movement discrimination task. Matin and Kibler interpreted their data in terms of the traditional psychophysical measures of a "just noticeable difference" (JND) and "point of subjective equality" (PSE). According to our theoretical model, these statistics are not appropriate since
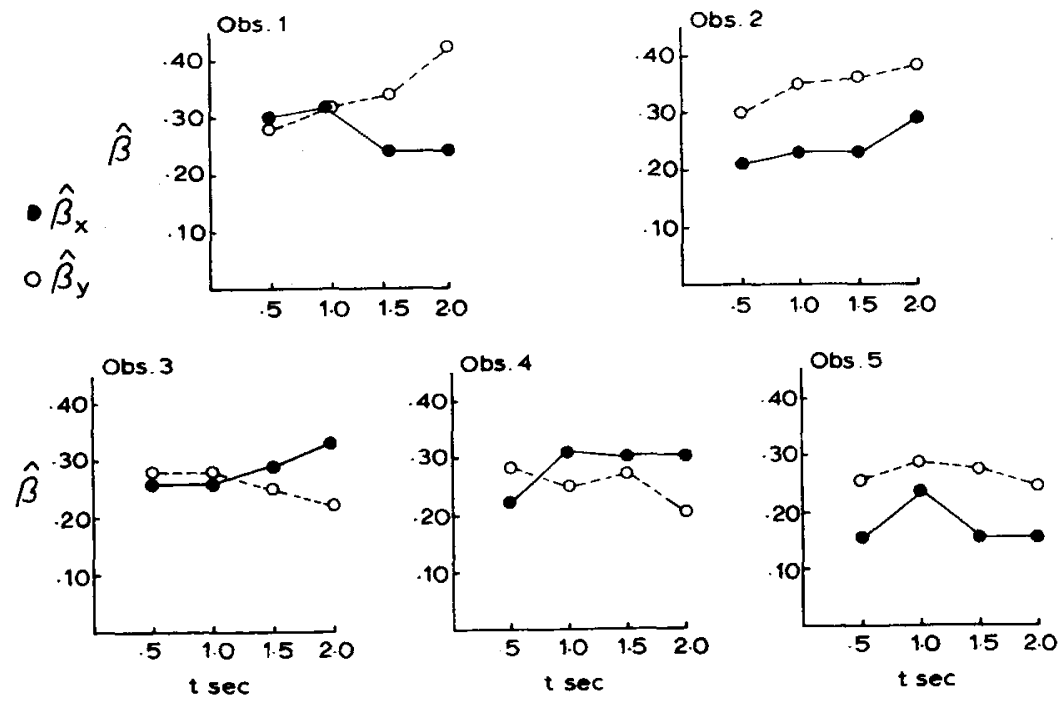

steps on both forms of the task. If we denote a report of positive movement by $R_{1}$, negative movement by $R_{2}$, and no movement by $R_{0}$, an $O$ 's performance on either form of the task can be summarized by proportions of the form $\hat{P}\left(R_{i} \mid S_{m}\right)$ for $i$ equal 0,1 , or 2 and $m$ equal to each of the nine values. These proportions for the three Os in both the vertical and horizontal tasks are presented graphically in Fig. 4, with each proportion based on 48 presentations of a particular stimulus pattern.

The one-dimensional movement discrimination model can be applied to these data if one assumes that each $O$ adopts two response criteria instead of one. Specifically, if the "subjective movement" produced on a particular trial is greater than some number $\beta_{1}$ he makes an $R_{1}$ response, if it is less than $\beta_{1}$ but greater than $\beta_{2}$ he makes an $R_{0}$ response, and if it is less than $\beta_{2}$ he makes an $R_{2}$ response. This decision process is illustrated in Fig. 5 . which presents theoretical distributions of subjective movement given particular $S_{m}$ values and two arbitrary $\beta$ values. The expected value of the subjective movement variable given stimulus pattern $S_{m}$ equals $m$, while its variance equals $\Phi \mathrm{t}$ (see Eqs. 1 and 2). In this case, $t$ was a constant $3 \mathrm{sec}$, so the only unknowns are $\Phi$ and the response criteria $\beta_{1}$ and $\beta_{2}$. Estimates of these theoretical parameters were obtained by simply selecting those that minimized the squared discrepancies between observed and predicted $P\left(R_{i} \mid S_{m}\right)$ values. Since there was virtually no difference in the $\Phi$ values based on the horizontal and vertical data from each $O$, a final set of estimates was obtained under the constraint that $\Phi$ was the same in both dimensions (although $\beta_{1}$ and $\beta_{2}$ could differ). These parameter estimates are presented in Table 5 and yield the theoretical curves in Fig. 4.

It is clear that the model provides a close fit to the data; the variability of the data points about the theoretical curves does not exceed that attributable to simple binomial sampling variance (based on the 48 trial proportions). Furthermore, while OGK $(\varphi=.077)$ appears to be more sensitive than the other two $(\Phi=.150$ and .170 ), there is no evidence of a difference in vertical and horizontal sensitivity; i.e., judgments on each dimension by any particular $O$ appear equally well fitted with a single $\Phi$ parameter and display no systematic divergencies from the predictions. The general magnitude of $\hat{\Phi}$ also seems consistent with the results of

Fig. 3. Estimated values of $\beta y$ and $\beta x$ in degrees of visual angle for each $O$. 

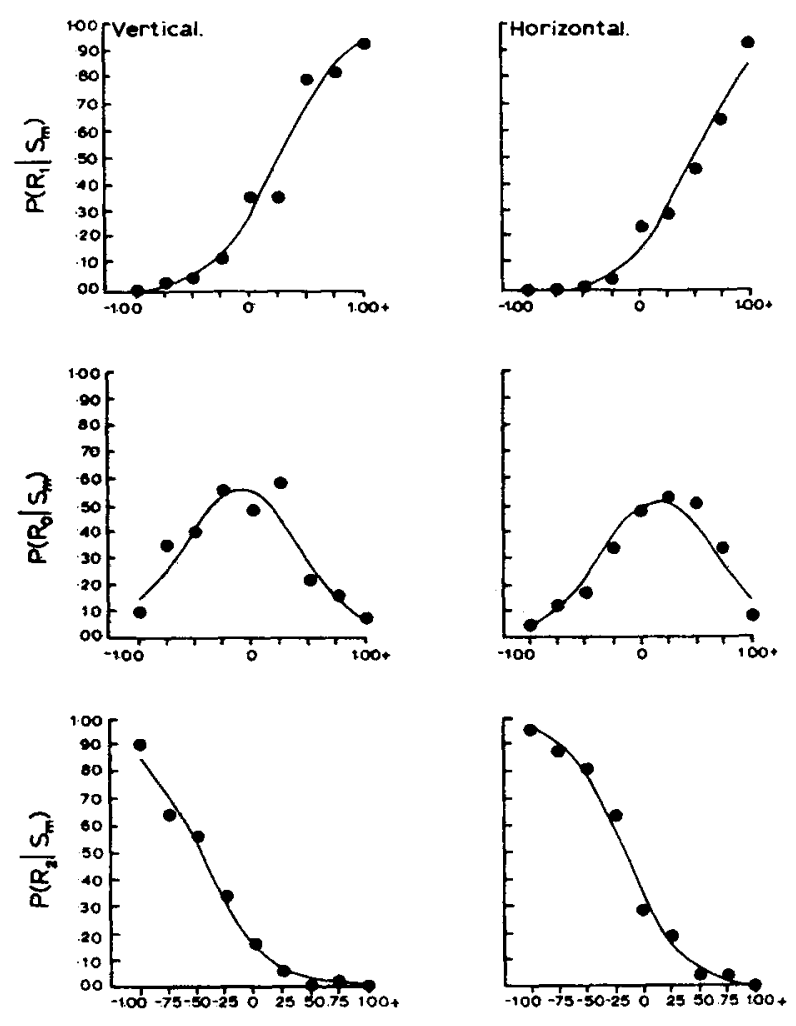

Obs. GEM $(\hat{\phi}=170)$
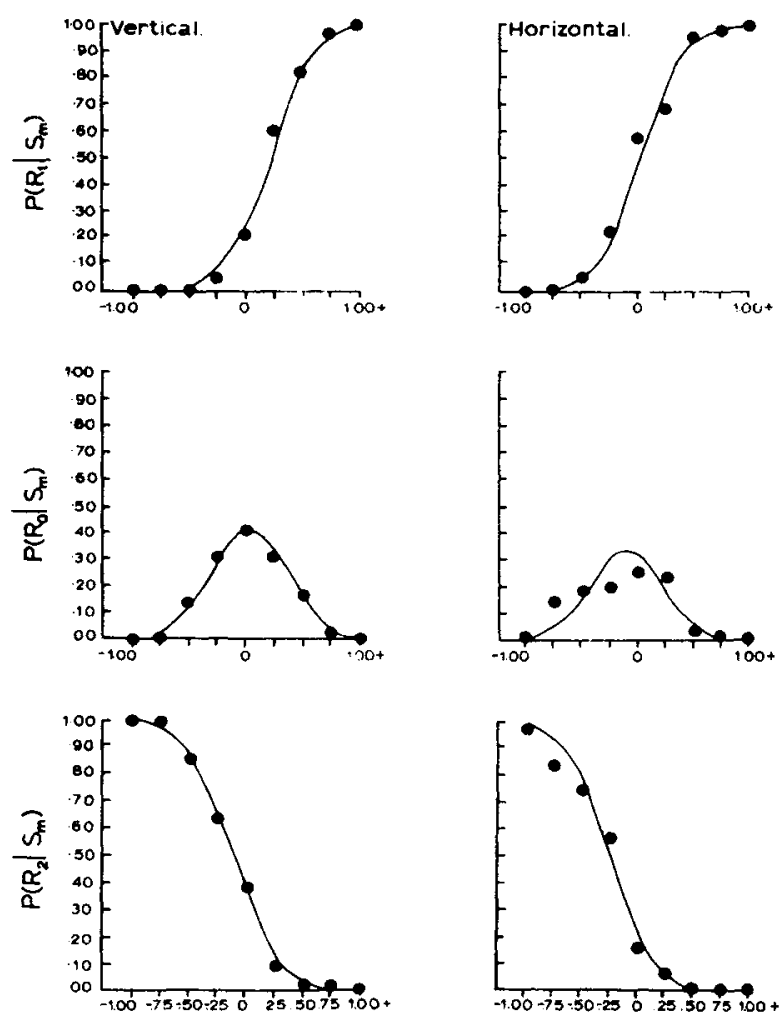

$\mathrm{m}$

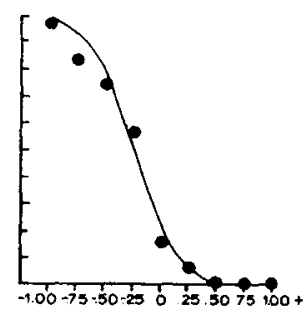

m
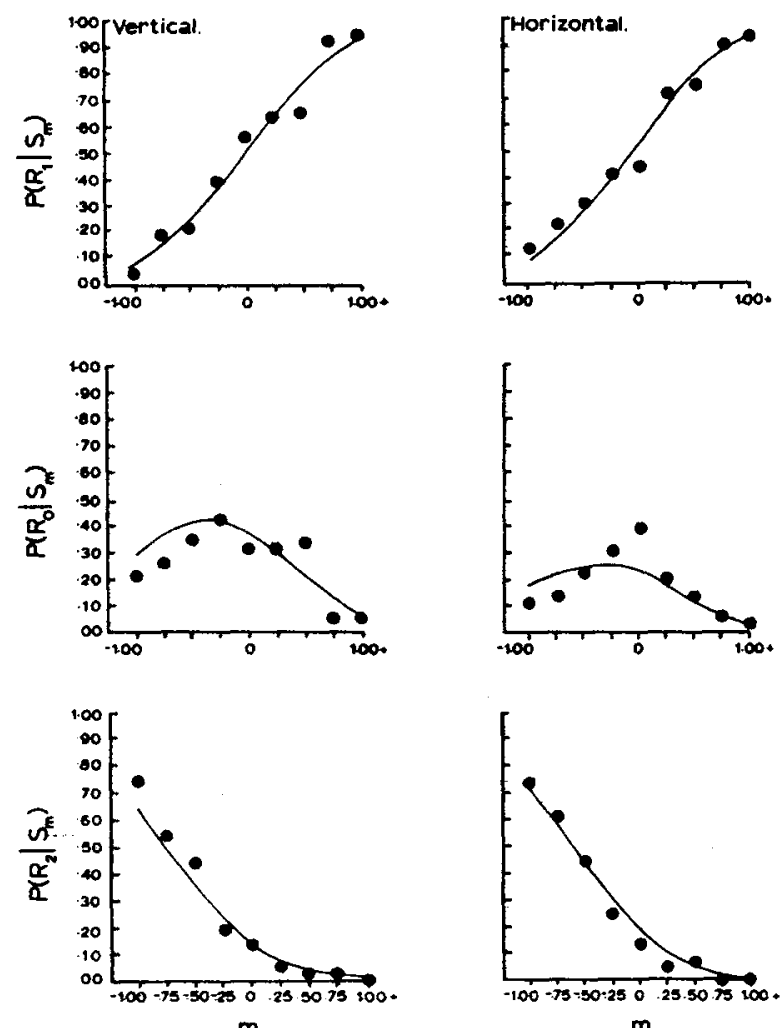

Fig. 4. Data from the Matin \& Kibler (1966) study and the model's predictions.
Table 5

Estimates of $\Phi$ and Response Criteria Based on the Matin \& Kibler (1966) Data

\begin{tabular}{|c|c|c|c|c|c|}
\hline \multirow{2}{*}{$\begin{array}{l} \\
8 \\
8 \\
0 \\
0\end{array}$} & \multirow[b]{2}{*}{$\hat{\Phi}$} & \multicolumn{2}{|c|}{ Vertical } & \multicolumn{2}{|c|}{ Horizontal } \\
\hline & & $\hat{\beta}_{2}$ & $\hat{\beta}_{1}$ & $\hat{\beta}_{2}$ & $\hat{\beta}_{1}$ \\
\hline $\begin{array}{l}\text { GK } \\
\text { DP } \\
\text { GEM }\end{array}$ & $\begin{array}{l}.077 \\
.150 \\
.170\end{array}$ & $\begin{array}{r}-.47 \\
-.75 \\
-.05\end{array}$ & $\begin{array}{l}.28 \\
.02 \\
.23\end{array}$ & $\begin{array}{r}-.17 \\
-.60 \\
-.60\end{array}$ & $\begin{array}{r}.50 \\
\cdots .12 \\
.04\end{array}$ \\
\hline
\end{tabular}

the experiment described in the preceding section. Each $O$ seems to have adopted unique response criteria with no consistent relation between the criteria in each dimension for all Os. For example, 0 GEM was somewhat more liberal in reporting vertical movement (only subjective vertical movement between - .05 and . 23 deg lead to $R_{0}$ ) than he was in reporting horizontal movement (subjective horizontal movement between -.60 and .04 deg lead to $R_{0}$ ). His judgmental standards were also asymmetrical within each dimension since he was more liberal in reporting movement down than up $\left(\left|\beta_{1}\right|>\left|\beta_{2}\right|\right)$, and more liberal in reporting movement right than left $\left(\left|\beta_{1}\right|<\left|\beta_{2}\right|\right)$. Similar idiosyncratic judgmental criteria are suggested by the performances of the other two Os.

Perception \& Psychophysics, 1970, Vol. 8 (6) 


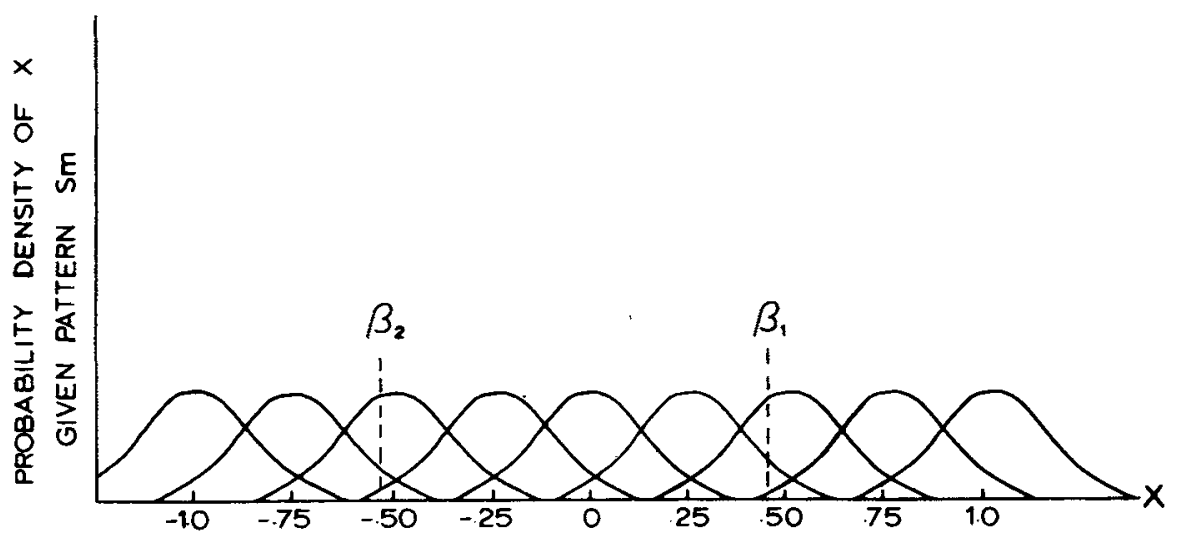

\section{CONCLUSIONS}

Our analysis appears to indicate that there is no consistent difference in an $O$ 's sensitivity to vertical and horizontal movement. While there is some suggestion of a small asymmetry in the data from two Os (Os 1 and 4 in the first experiment, Fig. 2) there is no evidence of any difference in the data from the other six Os we considered. Those dimensional asymmetries that do exist in an $O$ 's performance simply appear to be due to idiosyncratic judgmental standards.

With regard to the dimensional asymmetries in reports of autokinetic
Fig. 5. The theoretical decision problem for the $O$ in the Matin and Kibler (1966) nine-stimulus discrimination task.

HAYS, W. L. Statistics for psychologists. New York: Holt, Rinehart, \& Winston, 1963.

KINCHLA, R. A. Visual movement discrimination: Absolute and relative judgments. Technical Report No. 26, Psychology Series, McMaster University, 1968.

KINCHLA, R. A., \& ALLAN, L, G. A theory of visual movement perception. Psychological Review, 1969, 76, 537-558.

KINCHLA, R. A., \& SMYZER, F. A. A diffusion model of perceptual memory. Perception \& Psychophysics, 1967, 2, 219-229.

MATIN, L., \& KIBLER, G. B. Acuity of visual perception of direction in the dark for various positions of the eye in the orbit. Perceptual \& Motor Skills, 1966, 22, 407-420.

MATIN, L., \& MacKINNON, G. E. Autokinetic movement: Selective manipulation of directional components by image stabilization. Science, 1964, 143, 147-148.

ST. CYR, G. J., \& FENDER, D. H. The interplay of drifts and flicks in binocular fixation. Vision Research, 1969, 9, 245-265.

\section{NOTES}

1. The authors would like to express their appreciation to Lconard Matin for providing them with the data from the Matin \& Kibler (1966) study, and to Charles Collyer for experimental assistance.

2. Address: Department of Psychology, Green Hall, Princeton, New Jersey 08540.

GREEN, D. M., \& SWETS, J. A. Signal defection theory and psychophysics. New York: Wiley, 1966 .

(Accepted for publication April 3. 1970.) 